\title{
Overview of voluntarily stopping eating and drinking to hasten death
}

\author{
Jane Lowers, Sean Hughes, Nancy J. Preston \\ Lancaster University, Lancaster LA1 4YG, UK \\ Contributions: (I) Conception and design: None; (II) Administrative support: None; (III) Provision of study materials or patients: None; (IV) \\ Collection and assembly of data: None; (V) Data analysis and interpretation: None; (VI) Manuscript writing: All authors; (VII) Final approval of \\ manuscript: All authors. \\ Correspondence to: Jane Lowers, MPA. Emory University Palliative Care Program, 1841 Clifton Rd., Atlanta, GA 30329, USA. Email: jlowers@emory.edu.
}

\begin{abstract}
Voluntarily stopping eating and drinking is a means of hastening death. Unlike euthanasia or medical aid in dying, which are available only in certain jurisdictions and with assistance from health care professionals, the ability to die by voluntarily stopping eating and drinking is determined by ongoing patient choice, although clinical and caregiver support is recommended. Few studies have examined the incidence of patients choosing to stop eating and drinking; studies in the Netherlands and United States suggest patients choosing this route have concerns about both physical and existential suffering. This article presents an overview of voluntarily stopping eating and drinking, including guidance for clinicians, legal permissibility, and ethical discussions about whether the act constitutes suicide and how clinicians might respond to requests for information or support.
\end{abstract}

Keywords: Dehydration; palliative care; hospice care; intention; euthanasia

Submitted Nov 21, 2019. Accepted for publication May 22, 2020.

doi: $10.21037 /$ apm-19-525

View this article at: http://dx.doi.org/10.21037/apm-19-525

In this article, the medical, legal, and ethical position of voluntarily stopping eating and drinking (VSED) as a form of hastened death are outlined, as well as the limited available research on VSED. VSED is a term used to describe a deliberate, planned effort to hasten death.

Voluntarily stopping eating and drinking (VSED) is a "an action of a competent, capacitated person, who voluntarily and deliberately chooses to stop eating and drinking with the primary intention to hasten death because unacceptable suffering persists" (1). Distinct from cachexia that may be a natural stage in the advancement of some diseases, VSED is an ongoing voluntary choice to forego food and hydration. Unlike euthanasia, assisted suicide, or medical aid in dying (subsequently referred to as AID), VSED does not require lethal medication or a physician's order, although symptom management is recommended and ongoing support from caregivers is necessary $(1,2)$.

In this review VSED is used to denote the activity of a patient carrying out a personal choice not to eat or drink in order to hasten death, regardless of the level of planning or clinician (in this review, referring to physicians and nurses) involvement. However, recently Stangle et al. (3) have suggested that it may be useful to consider subtypes of VSED. Whereas many patients initiating VSED do so with explicit commitments of support from family or other caregivers and clinicians, Swiss research (3) has identified concealed VSED, in which an individual undertakes VSED in secret because of objections from caregivers. A second subtype is implicit nutrition refusal, in which the patient does not hide an intention to stop eating and drinking but does not explicitly express their decision to die (3). The latter case, Stangle suggests, may be less an expression of autonomy than of fatigue with life, and suggests that clinicians need to evaluate and understand patients' refusal to eat or drink and offer holistic care consistent with the patient's goals and values. 
Table 1 Stages of VSED $(6,10)$

\begin{tabular}{|c|c|c|c|c|}
\hline Stage & Duration & Patient status & Symptoms & Management \\
\hline Middle & Variable & $\begin{array}{l}\text { Weakening, more } \\
\text { sleep }\end{array}$ & Thirst, weakness, delirium & $\begin{array}{l}\text { Oral care; treatment for anxiety, delirium or pain; help } \\
\text { with transfers }\end{array}$ \\
\hline Late & $1-4$ days & $\begin{array}{l}\text { Largely unresponsive, } \\
\text { coma }\end{array}$ & $\begin{array}{l}\text { Unconsciousness, pain, } \\
\text { delirium }\end{array}$ & $\begin{array}{l}\text { Turns, repositioning, palliative sedation or pain } \\
\text { management }\end{array}$ \\
\hline
\end{tabular}

\section{Incidence}

Few studies have looked specifically at the incidence of VSED. Among 571 Japanese hospice and palliative physicians, $32 \%$ had experience with a patient choosing VSED (4). A survey of Swiss nursing home directors estimated that $1.7 \%$ of nursing home residents died by VSED (5). Dutch studies have produced estimates of $0.4 \%$ to $2.1 \%$ of annual deaths $(6,7)$, and in a survey of Dutch family physicians, $46 \%$ reported having cared for a person who elected VSED (8). In a 2001 survey mailed to Oregon hospice nurses (9), $41 \%$ of respondents reported having cared for a patient who attempted or completed VSED. Among the 102 cases reported in that survey, patients' average age was $74,54 \%$ were women, $48 \%$ were married, and $48 \%$ were widowed, divorced, or unmarried. Cancer was the most frequent diagnosis (60\%), followed by neurologic $(23 \%)$ or cardiovascular disease $(16 \%)$. In the Dutch study, physicians reported that $39 \%$ of patients had a somatic illness other than cancer, $27 \%$ had cancer, $12 \%$ had early dementia, and $24 \%$ had no severe physical or psychological disease (physicians could choose more than one diagnosis per patient) (8).

Nurses reported readiness to die, poor quality of life or fear of poor quality of life, viewing continued existence as pointless, desire to die at home, and desire to control the circumstances of death as among the most common reasons for choosing VSED (9). Somatic issues, such as pain, fatigue, or dyspnea, or fear of them were also common. However, in the survey of Dutch physicians, somatic motives were listed most often, followed by existential concerns or fears of dependence as the primary reasons for choosing VSED $(6,8)$. Both studies were based on clinician perception of patients' reasoning. Dutch guidance on VSED notes that many individuals seeking VSED in the Netherlands may be doing so because they have made a request for euthanasia that was declined (6).

\section{Clinical course}

VSED generally is described in three stages: an early stage in which the patient is alert and may experience thirst but can engage with others; a middle stage marked by progressive weakness as renal function fails; and a late stage in which the patient is largely unresponsive until death $(2,6,10)$ (See Table 1). Symptoms related to VSED include thirst and difficult urination, particularly in the first few days. Patients rarely express intolerable hunger because the body begins metabolising fats through ketosis (10). As dehydration continues, patients become weaker and may experience delirium. Patients become sleepier over time and may lapse into a coma several days before death. Depending on the patient's underlying health and how strictly they limit fluid intake, patients typically die within two weeks of initiating VSED $(6,9)$. Death is described as peaceful $(1,9)$ and thought to be caused by cardiac arrest as sodium and potassium transport in heart cells is disrupted (6).

Recommendations for symptom management during VSED, based on clinician experience, include oral swabs, mist sprays, lotion, and room humidification to ease dry mouth and other symptoms of dehydration as even small sips of water or ice chips adding up to $50 \mathrm{~mL} /$ day or more can slow dehydration and prolong dying $(6,10,11)$. As patients become weaker, they require assistance with toileting and hygiene, and eventually need help turning as they become bed-bound. Because thirst can lead to anxiety, clinical guidance includes having benzodiazepines available, as well as antipsychotics if required for severe delirium (2). Other palliative measures, including palliative sedation, may be required for patients with severe ongoing agitation (12). Hospice support is recommended if possible, although some hospices, such as those adherent to Catholic principles, may prefer not to be involved with attempts to deliberately hasten death and others may require the patient to have already initiated VSED $(10,13)$. 
One risk in attempting VSED is that, in delirium, the patient will forget his or her goals and will request water or food $(10,12)$. Medical and nursing guidance on VSED suggests that patients and caregivers plan in advance how to manage these situations, generally by reminding them of their goals and explaining that they can have fluids if they wish, but that doing so will work against their goals $(10,12)$. In addition, some patients change their mind whilst still cognizant $(10,14)$ and halt the process, and caregivers must be prepared for either outcome.

\section{Guidance for clinicians}

For clinicians who receive a request for information about or support for VSED, current guidance begins with a clinical evaluation to determine the nature of the patient's current or anticipated suffering, with treatment or specialty referral to address symptoms if necessary (10). Wax et al. suggest that clinicians address patient inquiries about VSED promptly, particularly for patients with conditions causing cognitive decline who may have a short window in which to consider or initiate VSED. Assessment also should include potential for coercion, as well as screening for psychiatric conditions such as depression or eating disorders that may be treatable (6). Dutch guidance on the clinicians' role in responding to VSED requests includes the recommendation to advise patients younger than 60 who do not have a lifethreatening illness against the choice of VSED, because of the likelihood that a healthy body with good kidney function will experience greater thirst and retain more fluid, prolonging the process (6).

Wax et al. (2018) suggest that patients intent on pursuing VSED complete appropriate advance directives such as do-not-resuscitate orders and enroll in hospice before or shortly after initiating VSED if possible (10). Finally, they note that VSED requires "significant social support" (10) (p443) and suggest that patients and caregivers need a clear plan for managing requests for food or water if the patient becomes delirious.

\section{Legal and ethical aspects of VSED}

VSED has been described as "not illegal" in the United States (2). It is not specifically described in law, and little relevant legal precedent has been set, either related to patients undertaking it or clinicians aiding patients in their VSED effort (2). In the United States, scholars place refusal to eat and drink within the context of legally protected self-determination (15), for which precedent includes a 1914 legal case in which a patient underwent a surgical procedure without consent: "Every human being of adult years and sound mind has a right to determine what shall be done with his own body; and a [physician] who performs [an intervention] without his patient's consent... is liable in damages" (16). This and other case law, and the constitutional right to privacy, protect patients' rights to refuse medical treatment, including discontinuing life-sustaining medical treatment such as artificial nutrition and hydration (15).

More ambiguous is whether natural nutrition and hydration are medical treatment. Pope cites two cases in which U.S. courts have ruled that feeding in a care setting constituted medical treatment (15). However, in longterm care settings in the United States, administrators may view provision of food and drink as part of basic care, such as toileting or bathing, rather than medical care (17). Federal guidance for safety surveyors requires that facilities' "actual food and nutrition services meet each resident's daily nutritional and dietary needs and choices" (18), and administrators may fear being charged with abuse or neglect $(17,18)$. Pope and Anderson argue that although regulations are intended to guard against patients not receiving wanted nutrition and hydration, U.S. federal rules also allow longterm care residents to refuse treatment (17). An Australian court found similarly in $H$ Ltd. V.F \& Anor, which clarified that there is "no common law duty to provide nutrition and hydration to a competent adult who refused it" and found that such a refusal was not suicide but a speeding of natural death $(15,19)$. In Canada, two courts ruled that a competent individual cannot be compelled to eat or drink against his or her wishes $(15,20,21)$. Additionally, in a 2014 decision, the Supreme Court of British Columbia found that a healthcare provider could act on an advance directive requesting VSED for a patient who subsequently lost capacity. However, in the case in question, that of Margot Bentley, a retired nurse with dementia, the court found the patient's advance directive to be inadequately worded to clearly convey her intent about oral food and fluid $(15,22)$.

In the Netherlands, guidance for clinicians notes that suicide is not a criminal act, and that VSED may not be equivalent to suicide because the latter is associated "with an active, violent, lonely, and often impulsive act” (6) (p23).

Beyond legal issues, patients considering VSED, their family or caregivers, and their clinicians may have ethical or moral concerns about the process, specifically whether it is a form of suicide, whether suicide is always morally wrong, and whether clinicians who oppose suicide have 
an obligation to support a patient who has elected VSED $(2,10,12,23)$. Proponents of the permissibility of VSED note that suicide may be rational if patients are choosing a deliberate death by known means—a harm-over perceived greater harm, such as prolonged suffering from illness that will also end in death (24). VSED also is perceived as less likely than AID to be a coerced choice: "VSED requires a sustained determination of the patient's own will despite substantial discomforts such as thirst and hunger. Furthermore, decisions to undertake VSED can be reversed by the patient, at least in the early phases. Among other 'last resort' decisions, VSED raises the fewest concerns that the choice is voluntary" (2) (p125).

In an extensive legal review of VSED, Pope and Anderson (17) outline four distinctions between VSED and physician-aided suicide that might make VSED less objectionable to clinicians or others who won't support active measures to hasten death in the context of U.S. law:

- Refusal of medical treatment is legal, and handfeeding has been legally established in the United States as a medical treatment.

* Laws related to suicide frame it as "active interventions such as the introduction of a lethal agent," (p420) whereas VSED is passive: it is an omission rather than an act.

* Unlike AID, which is involves a request from the patient for the doctor to provide the patient with a harm, VSED is a request not to have unwanted things done to the patient, such as having food or liquid forcibly introduced. "The doctor cannot owe the patient any duty to maintain his life where that life can only be sustained by intrusive medical care to which the patient will not consent." (p421)

* VSED has no exterior cause of death: Rather than ingesting a fatal, physician-supplied substance, the patient instead allows the natural biological process of excreting liquid to continue without taking in liquid to counteract it. The patient's own biology, not a clinician's steps to reduce suffering, causes the death.

Quill et al. (2018) note two opposing viewpoints on the role of clinicians in VSED. One is that suicide is immoral and any effort to facilitate it, such as by managing symptoms of VSED, is morally and possibly legally wrong. The other is that suffering, whether from symptoms related to VSED or other causes, should be met with palliative care if desired (2). Jansen and Sulmasy suggest a third position in between, that it could be permissible for a physician to support a patient's choice to refuse treatment, including nutrition and hydration, in the face of terminal suffering, but that the physician should not suggest it as an option lest the patient be influenced to choose it (25).

\section{Emerging issues in VSED}

In recent years, VSED has been proposed as a means for individuals with a dementia diagnosis to avoid living through the disease's later stages, when the individual can no longer recognize loved ones or perform basic self care. Advocates in New York created an advance directive form that allows individuals, in advance, to refuse oral assisted feedings once they have lost the ability to self-feed and make decisions, or to limit oral intake to comfort feeding only as long as the patient is interested and willing (26). A law passed in May 2019 by the Nevada state legislature makes the state the first to allow residents to create an advance directive for dementia, including the ability to specify that care providers should stop administering food and fluid by mouth (27). To date there has been little published research on VSED, limited to surveys of clinicians' impressions of patients' reasons for undertaking VSED $(4,5,8,9)$. Future research could explore patients' motivations for pursuing VSED and patient and caregiver experience with the process itself, differences in VSED internationally, and cultural, religious, or socio-economic influences on VSED experience.

\section{Conclusions}

VSED may be more common than physician-assisted forms of dying simply because it falls beneath the level of legal scrutiny except in some cases involving institutional settings. VSED requires a prolonged act of will by the patient and generally some level of support from caregivers and clinicians. Research to date has focused on clinicians' perceptions of both the incidence of VSED and patients' reasons for pursuing it, but little research has been done overall (1). Future research could explore the demographic and clinical diversity, motivations and experiences of patients themselves and the experiences of caregivers who may be best positioned to observe the full course of VSED. Individual clinicians' and caregivers' uncertainty about whether VSED constitutes suicide is an obstacle to largescale studies of the true prevalence of VSED.

\section{Acknowledgments}

Funding: None. 


\section{Footnote}

Provenance and Peer Review: This article was commissioned by the editorial office, Annals of Palliative Medicine for the series "Hastened Death". The article has undergone external peer review.

Conflicts of Interest: All authors have completed the ICMJE uniform disclosure form (available at http://dx.doi. org/10.21037/apm-19-525). The series "Hastened Death" was commissioned by the editorial office without any funding or sponsorship. NP served as the unpaid Guest Editor of the series and serves as an unpaid editorial board member of Annals of Palliative Medicine from May 2019 to April 2021. The authors have no other conflicts of interest to declare.

Ethical Statement: The authors are accountable for all aspects of the work in ensuring that questions related to the accuracy or integrity of any part of the work are appropriately investigated and resolved.

Open Access Statement: This is an Open Access article distributed in accordance with the Creative Commons Attribution-NonCommercial-NoDerivs 4.0 International License (CC BY-NC-ND 4.0), which permits the noncommercial replication and distribution of the article with the strict proviso that no changes or edits are made and the original work is properly cited (including links to both the formal publication through the relevant DOI and the license). See: https://creativecommons.org/licenses/by-nc-nd/4.0/.

\section{References}

1. Ivanovic N, Buche D, Fringer A. Voluntary stopping of eating and drinking at the end of life - a 'systematic search and review' giving insight into an option of hastening death in capacitated adults at the end of life. BMC Palliat Care 2014;13:1.

2. Quill TE, Ganzini L, Truog RD, et al. Voluntarily Stopping Eating and Drinking Among Patients With Serious Advanced Illness-Clinical, Ethical, and Legal Aspects. JAMA Intern Med 2018;178:123-7.

3. Stängle S, Schnepp W, Fringer A. The need to distinguish between different forms of oral nutrition refusal and different forms of voluntary stopping of eating and drinking. Palliat Care Soc Pract 2019;13:1178224219875738.
4. Shinjo T, Morita T, Kiuchi D, et al. Japanese physicians' experiences of terminally ill patients voluntarily stopping eating and drinking: a national survey. BMJ Support Palliat Care 2019;9:143-5.

5. Stangle S, Schnepp W, Buche D, et al. Long-term care nurses' attitudes and the incidence of voluntary stopping of eating and drinking: A cross-sectional study. J Adv Nurs 2020;76:526-34.

6. Royal Dutch Medical Association. Caring for people who consciously choose not to eat and drink so as to hasten the end of life. Utrecht; 2014.

7. Chabot BE, Goedhart A. A survey of self-directed dying attended by proxies in the Dutch population. Soc Sci Med 2009;68:1745-51.

8. Bolt EE, Hagens M, Willems D, et al. Primary care patients hastening death by voluntarily stopping eating and drinking. Ann Fam Med 2015;13:421-8.

9. Ganzini L, Goy ER, Miller LL, et al. Nurses' Experiences with Hospice Patients Who Refuse Food and Fluids to Hasten Death. N Engl J Med 2003;349:359-65.

10. Wax JW, An AW, Kosier N, et al. Voluntary Stopping Eating and Drinking. J Am Geriatr Soc 2018;66:441-5.

11. Shacter P. Choosing to Die: A Personal Story. United States of America: Phyllis Shacter; 2017.

12. Schwarz J. Exploring the option of voluntarily stopping eating and drinking within the context of a suffering patient's request for a hastened death. J Palliat Med 2007;10:1288-97.

13. Cavanagh M. How should a Catholic hospice respond to patients who choose to voluntarily stop eating and drinking in order to hasten death? Linacre Q 2014;81:279-85.

14. Schwarz JK. Sarah's Second Attempt to Stop Eating and Drinking: Success at Last. Narrat Inq Bioeth 2016;6:99-101.

15. Pope TM, West A. Legal briefing: voluntarily stopping eating and drinking. J Clin Ethics 2014;25:68-80.

16. Schloendorff $\mathrm{v}$ Society of New York Hospitals, 105 N.E. 92, 93 (1914). Available online: https://biotech.law.lsu.edu/ cases/consent/schoendorff.htm

17. Pope TM, Anderson LE. Voluntarily Stopping Eating and Drinking: A Legal Treatment Option at the End of Life. Widener Law Review 2011;17:363-427.

18. State Operations Manual Appendix PP - Guidance to Surveyors for Long Term Care Facilities, $\$ 483.60$ (2017).Available online: https://www.cms.gov/ Medicare/Provider-Enrollment-and-Certification/ GuidanceforLawsAndRegulations/Downloads/AppendixPP-State-Operations-Manual.pdf 
19. H Ltd v J \& Anor, [2010] SASC 176 (2010). Available online: https://www.mondaq.com/australia/ healthcare/115906/end-of-life-decisions-h-limited-v-j2010-sasc-176

20. Manoir de la Pointe bleue (1978) inc c. Corbeil, (1992). Available online: http://www.vosdroitsensante.com/ documents/file/manoir-de-la-pointe-bleue-c-corbeil.pdf

21. British Columbia (Attorney General) v. Astaforoff, (1983). Available online: https://scc-csc.lexum.com/scc-csc/scccsc/en/item/366/index.do

22. Bentley v Maplewood Seniors Care Society, BCSC 165 (2014). Available online: https://www.bccourts.ca/jdb-txt/ SC/14/01/2014BCSC0165.htm

23. Gerson SM, Preston N, Bingley A. Medical Aid in Dying, Hastened Death and Suicide: A Qualitative Study of Hospice Professionals' Experiences from Washington State. J Pain Symptom Manage 2020;59:679-686.e1.

24. Bernat JL, Gert B, Mogielnicki RP. Patient refusal of

Cite this article as: Lowers J, Hughes S, Preston NJ. Overview of voluntarily stopping eating and drinking to hasten death. Ann Palliat Med 2021;10(3):3611-3616. doi: 10.21037/apm-19-525 hydration and nutrition. An alternative to physicianassisted suicide or voluntary active euthanasia. Arch Intern Med 1993;153:2723-8.

25. Jansen LA. Voluntary Stopping of Eating and Drinking (VSED), Physician-Assisted Suicide (PAS), or Neither in the Last Stage of Life? PAS: No; VSED: It Depends. Ann Fam Med 2015;13:410-1.

26. Dementia Advance Directive. About the Advance Directive for Receiving Oral Food and Fluids in Dementia. End of Life Choices New York.

27. SB121. AN ACT relating to fiduciaries; adopting a power of attorney for health care decisions for persons with any form of dementia; revising provisions relating to the authority of a principal under a power of attorney; revising provisions governing the authority of public guardians to conduct certain investigations; and providing other matters properly relating thereto. 2019. 